\title{
Trends in incidence, mortality and survival in women with breast cancer from 1985 to 2012 in Granada, Spain: a population-based study
}

José Antonio Baeyens-Fernández ${ }^{*}$ (D), Elena Molina-Portillo 2,3, Marina Pollán ${ }^{3,4}$, Miguel Rodríguez-Barranco 2,3, Rosario Del Moral ${ }^{3,5}$, Lorenzo Arribas-Mir ${ }^{6,7}$, Emilio Sánchez-Cantalejo Ramírez ${ }^{2,3}$ and María-José Sánchez ${ }^{2,3}$

\begin{abstract}
Background: The incidence of breast cancer has increased since the 1970s. Despite favorable trends in prognosis, the role of changes in clinical practice and the introduction of screening remain controversial. We examined breast cancer trends to shed light on their determinants.

Methods: Data were obtained for 8502 new cases of breast cancer in women between 1985 and 2012 from a population-based cancer registry in Granada (southern Spain), and for 2470 breast cancer deaths registered by the Andalusian Institute of Statistics. Joinpoint regression analyses of incidence and mortality rates were obtained. Observed and net survival rates were calculated for 1, 3 and 5 years. The results are reported here for overall survival and survival stratified by age group and tumor stage.

Results: Overall, age-adjusted (European Standard Population) incidence rates increased from 48.0 cases $\times 100,000$ women in 1985-1989 to 83.4 in 2008-2012, with an annual percentage change (APC) of $2.5 \%(95 \% \mathrm{Cl}, 2.1-2.9)$ for 1985-2012. The greatest increase was in women younger than 40 years (APC 3.5, 95\%Cl, 2.4-4.8). For 2000-2012 the incidence trend increased only for stage I tumors (APC 3.8, 95\% Cl, 1.9-5.8). Overall age-adjusted breast cancer mortality decreased (APC $-1,95 \% \mathrm{Cl},-1.4--0.5$ ), as did mortality in the $50-69$ year age group (APC $-1.3,95 \% \mathrm{Cl}$, $-2.2--0.4$ ). Age-standardized net survival increased from $67.5 \%$ at 5 years in $1985-1989$ to $83.7 \%$ in $2010-2012$. All age groups younger than 70 years showed a similar evolution. Five-year net survival rates were $96.6 \%$ for patients with tumors diagnosed in stage I, $88.2 \%$ for stage II, $62.5 \%$ for stage III and $23.3 \%$ for stage IV.

Conclusions: Breast cancer incidence is increasing - a reflection of the evolution of risk factors and increasing diagnostic pressure. After screening was introduced, the incidence of stage I tumors increased, with no decrease in the incidence of more advanced stages. Reductions were seen for overall mortality and mortality in the 50-69 year age group, but no changes were found after screening implementation. Survival trends have evolved favorably except for the 70-84 year age group and for metastatic tumors.
\end{abstract}

Keywords: Cancer, Breast, Trend, Population-based, Incidence, Mortality, Survival, Stage, Registry, Spain

\footnotetext{
* Correspondence: jabfdez@gmail.com

1Departamento de Urgencias y Emergencias, Área de Gestión Sanitaria

Noreste, Hospital Regional de Baza, Carretera de Murcia s/n, 18800 Baza,

Spain

Full list of author information is available at the end of the article
}

(c) The Author(s). 2018 Open Access This article is distributed under the terms of the Creative Commons Attribution 4.0 International License (http://creativecommons.org/licenses/by/4.0/), which permits unrestricted use, distribution, and reproduction in any medium, provided you give appropriate credit to the original author(s) and the source, provide a link to the Creative Commons license, and indicate if changes were made. The Creative Commons Public Domain Dedication waiver (http://creativecommons.org/publicdomain/zero/1.0/) applies to the data made available in this article, unless otherwise stated. 


\section{Background}

Breast cancer is the most frequent tumor in women worldwide, particularly in countries with a high Human Development Index [1]. Moreover, it is one of the leading causes of cancer mortality in females. In 2015 there were 2.4 million estimated new cases and 523,000 estimated deaths worldwide in women, which correspond to about $29 \%$ of the total incident cancer cases and $14 \%$ of all cancer deaths [2]. There is huge variability in the incidence among countries, from 27 cases per 100,000 women in Asia to 97 per 100,000 white women living in the USA [3]. In Spain, the 2015 age-standardized incidence rate referred to the world population (ASR-W) was 65.2 per 100,000 women and the age-standardized incidence rate referred to the European population (ASR-E) was 88.3 per 100,000 women, placing this country in an intermediate position worldwide [4].

Several industrialized countries including Spain have shown a 30 to $40 \%$ increase in breast cancer incidence since the 1970s [3, 5]. This rise has been related to the spread of environmental and lifestyle risk factors, and to changes in diagnostic patterns $[3,6,7]$. A trend change has been observed since the beginning of the twenty-first century, mainly among women older than 50 years [8-10]. The main factors related to this change are the implementation of population-based screening programs at a country-wide level, and (albeit with a relatively low impact in Spain), the evolution of prescribing practices for hormonal replacement therapy $[8,11]$. Analysis of breast cancer incidence trends in young women vary widely among countries, but in general show a steady increase since the early 1980s even in countries where the incidence in older age groups has decreased [12-14]. Studies in European countries and in the US show an increase in the incidence of early-stage tumors and a parallel reduction in late-stage tumors, although this reduction seems to be smaller than expected and the incidence of metastatic breast cancer has remained stable [15-18]. In Spain, there are no available population-based data on breast cancer incidence trends by stage.

Breast cancer mortality in Europe showed an increasing trend until the 1990s [3]. Between 1989 and 2006, breast cancer mortality (ASR-E) in European countries reportedly declined by a median of $19 \%$ [19]. The world-standardized mortality rate in Europe decreased from 21.3 in 1990 [20] to 16.7 deaths per 100,000 women in 2007 [21]. Finally, in Spain, the mortality rate (ASR-W) dropped from 17.3 per 100,000 women in 1995 to 10.8 per 100,000 in 2014 [22]. This reduction in mortality has been consistently smaller in women older than 70 years $[5,19]$, and correlates with the development of adjuvant treatments and, to a lesser extent, with the introduction of screening [23, 24].

Survival rates for breast cancer have generally increased since the 1980s. This trend has been related with a higher proportion of cases diagnosed at earlier stages as well as therapeutical improvements [25]. Currently, the 5 -year net survival rate is higher than $85 \%$ in seventeen countries worldwide. In Europe the median survival rate ranges from 81 to $84 \%$, with the exception of Eastern countries, where the survival rate is around 69\% [26, 27]. However, no relevant increase in overall survival has been observed for metastatic tumors, or in the group of women older than 70 years $[26,28]$. Spain had a 5-years survival rate of $78.4 \%$ for women diagnosed between 1997 and 1999 , and this rate increased to $82.8 \%$ for those diagnosed between 2000 and 2007 [29]. Increasing trends in survival are related to early diagnosis and improvements in surgical and adjuvant treatments. Several recent studies have improved our understanding about the role played by screening, the spread of adjuvant treatments and their adverse effects, but there is still considerable controversy on this issue [30-32].

Since 1985 the Granada Cancer Registry (southern Spain) has systematically compiled data on breast cancer incidence, mortality, and crude and net survival trends. We were able to use the data collected for a period of more than 28 years from 1985 to 2012. In addition, we analyzed a subset of the data for the years 2000 to 2012, after the implementation of a screening program in 1998. For this period, we analyzed breast cancer incidence trends according to disease stage, to shed light on the impact of screening on stage distribution and its association to mortality and survival trends. To date no such analysis has been undertaken in Spain, as far as we are aware.

Determinants of breast cancer trends have been identified in previous studies, but unresolved controversies remain about their role. Trends studies provide an excellent opportunity to explore the specific weight of each factor. Studies at regional or national level frequently only consider either incidence or mortality [8, 15, 33, 34]. However, we present a comprehensive population-based analysis of breast cancer epidemiology, including every indicator and age group - an approach which facilitates an integral interpretation of the factors that may influence trends. Moreover, our analysis of tumor stages at diagnosis, together with the long observation period, hold the potential to provide a better understanding of trend determinants and especially the influence of breast cancer screening.

\section{Methods}

\section{Participants and data sources}

The population data were from the Granada Cancer Registry, a population-based cancer registry in southern Spain launched in 1985 and covering a population of about 922,100 inhabitants (50.3\% women) (2011 population census of Granada. Source: Statistics and Cartography 
Institute of Andalusia http://www.juntadeandalucia.es/ institutodeestadisticaycartografia).

A total of 8502 women residing in Granada province were diagnosed with a first primary invasive breast cancer, and 2470 breast cancer deaths were registered between January 1st 1985 and December 31st 2012. The Granada Cancer Registry uses as information sources public and private hospitals at the local and regional levels, oncology and pathology department records, and death certificates. Mortality data were extracted from the database of the Institute of Statistics and Cartography of Andalusia (http://www.juntadeandalucia.es/institutodeestadisticaycartografia). Other sources of information used, when necessary and available, were the National Index of Deaths (http://www.msssi.gob.es/estadEstudios/estadisticas/ estadisticas/estMinisterio/IND_TipoDifusion.htm), the Social Security Database (http://www.seg-social.es/wps/portal/ wss/internet/EstadisticasPresupuestosEstudios/Estadisticas), municipal census information, and hospital and primary care records.

The data in this registry are published regularly in Cancer Incidence in Five Continents (CIFC) monographs. The quality of the data is supported by good indicators: $96 \%$ of breast cancer cases were confirmed histologically, and a death certificate was the only source of information for $1.8 \%$ of the cases. Moreover, the Granada Cancer Registry is a member of the European Network of Cancer Registries (ENCR) and the Spanish Network of Cancer Registries (REDECAN), and a collaborator in the EUROCARE (http://www.eurocare.it/) and CONCORD studies (http:// csg.lshtm.ac.uk/research/themes/concord-programme/).

\section{Study variables}

Standard international procedures for cancer registries and coding rules are used in the Granada Cancer Registry. Breast cancer is defined as code C50 according to the International Statistical Classification of Diseases and Related Health Problems, 10th revision [35].

Age was stratified in 5-year intervals for standardization, and in the following broader groups for specific analysis: less than 40 years, $40-49,50-69,70-84$, and 85 years or more. These groups have been established to focus on main topics concerning breast cancer trends, as has been done in previous analyses [13, 36-38]. Tumor stage at diagnosis was coded with the TNM system (6th edition for 2000-2010 and 7th edition for 2010-2012). Every case was re-coded according to the 7th edition [39].

Passive and active follow-up of cancer cases was carried out from the date of diagnosis to the end of follow-up (31 December 2014), when vital status was ascertained. The outcome variables were alive at the end of follow-up, death including date of exitus for any cause, or censored due to loss or incomplete follow-up.

\section{Statistical analysis}

The number of new cases and deaths, crude rates, and age-standardized mortality and incidence rates referred to the European population are reported here. ASR-E rates were calculated by weighting age-specific incidence rates to the standard European population, and are expressed per 100,000 women-years. For incidence and mortality rates, R software was used (https://www.r-project.org).

Joinpoint regression analysis [40] of age-standardized or age-specific incidence or mortality rates was used to estimate the annual percentage change (APC) in breast cancer incidence and mortality. The APC was calculated by fitting connections between log scale linear trends to the chronological year as the regressor variable, assuming constant variance and uncorrelated errors. In the regression analysis, up to three change points (four trend line segments) were allowed. Each trend line segment is expressed by an APC value. When no change points were found, only one APC value represented the trend line for the whole period.

Joinpoint regression was performed on data from the earliest available data until the last year of available data. Stage at diagnosis was not systematically recorded in the Granada Cancer Registry for any cancer until the year 2000. Therefore, Joinpoint analysis of breast cancer incidence according to stage was only performed for the period 2000-2012.

Increasing or decreasing trends were considered to exist for $p$ values $<0.05$. The APC and 95\% confidence intervals $(\mathrm{CI})$ were calculated for the whole population, and for age groups (0-39 years, 40-49, 50-69, 70-84, and 85 years or more) and by tumor stage at diagnosis (2000 to 2012). For all statistical analyses we used the Joinpoint regression program (v. 4.1.1) [40].

Observed survival was calculated with the Kaplan-Meier method for 5-year periods from 1985 to 2009, and for the last 3-year period from 2010 to 2012. Because comorbidities can influence death rates, net survival was also calculated. This was defined as survival for cases in which breast cancer was the only cause of death. Net survival was estimated with the Pohar-Perme method [41] and cohort analysis. For 2010-2012, period analysis was used because follow-up time was too short for cohort analysis [42]. Survival (standardized and non-standardized by age) was calculated for 1, 3 and 5 years from diagnosis. Survival estimates were limited to ages 15-99 years, and we excluded cases for which a death certificate was the only source of information and those diagnosed on autopsy. Survival analysis was done with the strs package for Stata software v. 14 [43].

The dataset of the population-based cancer registry is registered as stipulated by law within the Spanish Data Protection Agency (Agencia Española de Protección de Datos. https://www.agpd.es). All data collected in the 
database for incidence, mortality and survival analysis were anonymous, and no ethical approval was required.

\section{Results}

\section{Incidence 1985-2012}

During the period from 1985 to 2012, 8502 new cases of breast cancer were registered among women living in Granada province (Table 1). Breast cancer accounted for $25 \%$ of all cancer cases (excluding non-melanoma skin cancer) in women during this time, and the median age at diagnosis was 59 years. European age-standardized incidence rates increased from 48 cases per 100,000 women in 1985-1989 to 83.4 per 100,000 women in 2008-2012 (Table 1), with a statistically significant APC of $2.5 \%$ (95\% CI, 2.1-2.9).

Incidence trends by age group at diagnosis for the whole period showed an increase that was statistically significant in every age group, but differences were seen among groups (Fig. 1). A substantial proportion of cases (44.9\%) were diagnosed in women 50-69 years old, and the APC was $3.0 \%$ (95\%CI, 2.4-3.5). Age group 0-39 years accounted for $7.7 \%$ of all new cases, but presented the greatest increase (APC 3.5, 95\% CI, 2.4-4.7). Positive trends were found for groups 40-49 years (APC 2.3, 95\%CI, 1.5-3.0), 70-84 years (APC 2.0, 95\% CI, 1.3-2.7), and 85 years and older (APC 3.2, 95\%CI, 1.5-4.8) (Fig. 1).

\section{Incidence 2000-2012}

During this period 5120 new cases of breast cancer were registered, and incidence overall and for every age group showed a nonsignificant trend. An increase in incidence was found for stage I tumors (APC 3.8, 95\%CI, 1.9-5.8), whereas a decrease was found for all other stages, although none of them reached statistical significance (Fig. 2). Distribution by stage showed that $35.0 \%$ of tumors were diagnosed in stage I, and 39.0\% in stage II. Only 4.8\% of all diagnoses were stage IV tumors. Distribution of breast cancer cases according to stage at diagnosis is shown by age group in Table 2 and by chronological year in Table 3.

\section{Mortality 1985-2012}

The crude mortality rate for breast cancer during 19852012 in Granada province was 20.9 deaths per 100,000 women, corresponding to 2470 deaths. There was a decrease in ASR-E mortality from 20.5 to 15.2 per 100,000 women from 1985 to 1989 to 2008-2012 (Table 1). The mortality trend during the study period showed an annual decline (APC $-0.9,95 \% \mathrm{CI},-1.4--0.5$ ).

Breast cancer deaths occurred mostly in women older than 70 years, and this age group contributed $45.3 \%$ of all deaths. However, only women older than 85 years showed an increasing trend in mortality (APC 3.7, 95\%CI, 1.6-5.9) (Fig. 3). The rest of the age groups showed non-significant decreasing trends for this period, except the 50-69 year age group trend (APC - 1.3, $95 \% \mathrm{CI},-2.2--0.4)$.

\section{Mortality 2000-2012}

The overall trend for this period showed a nonsignificant annual decrease of $0.7 \%$. Stratification by age group showed a nonsignificant increasing trend in women aged $40-49$ years (APC $4.2,95 \% \mathrm{CI},-1.8-10.4$ ) and 85 years or more (APC 1.8, 95\%CI, $-2.3-6.1$ ). The number of deaths in these groups was 132 in the former and 180 in the latter (Table 4).

\section{Survival 1985-2012}

Both the observed and net age-standardized survival rates at 5 years increased steadily from $67.5 \%$ in 1985 1989 to $83.7 \%$ in $2010-2012$ (Table 5). The evolution of survival rates 1,3 and 5 years after diagnosis are illustrated in Fig. 4.

Age group analyses showed that survival tended to increase in groups younger than 70 years, with similar survival rates of approximately $90 \%$ in $2005-2009$ and $93 \%$

Table 1 Breast cancer mortality and incidence rates, and numbers of cases and deaths, 1985-2012

\begin{tabular}{|c|c|c|c|c|c|c|}
\hline \multirow[t]{2}{*}{ Period } & \multicolumn{3}{|c|}{ Incidence } & \multicolumn{3}{|c|}{ Mortality } \\
\hline & Cases & ASR-E* $^{*}$ & ASR-W* & Deaths & ASR-E* & ASR-W* \\
\hline 1985-1989 & 909 & 48.0 & 36.0 & 408 & 20.5 & 14.8 \\
\hline 1990-1994 & 1110 & 56.1 & 42.2 & 396 & 18.5 & 13.1 \\
\hline 1995-1999 & 1363 & 64.1 & 47.7 & 420 & 17.9 & 12.6 \\
\hline 2000-2004 & 1751 & 77.3 & 57.7 & 462 & 17.0 & 11.7 \\
\hline 2005-2009 & 2051 & 81.0 & 60.5 & 485 & 16.5 & 11.6 \\
\hline 2010-2012 & 1318 & 80.1 & 59.4 & 299 & 15.2 & 10.4 \\
\hline 2000-2012 & 5120 & 79.5 & 59.3 & 1.246 & 16.5 & 11.4 \\
\hline 1985-2012 & 8502 & 68.2 & 50.9 & 2.470 & 17.7 & 12.4 \\
\hline
\end{tabular}

Numbers of cases and deaths, and age-standardized incidence and mortality rates (ASR-E and ASR-W) are shown for each period analyzed and for the first and last 5-year follow-up. Population: 463816 women residing in Granada province (Source: 2011 population census for Granada, Statistics and Cartography Institute of Andalusia). ASR-W: age-standardized rate referred to world population; ASR-E: age-standardized rate referred to European population. ${ }^{*}$ per 100,000 women 


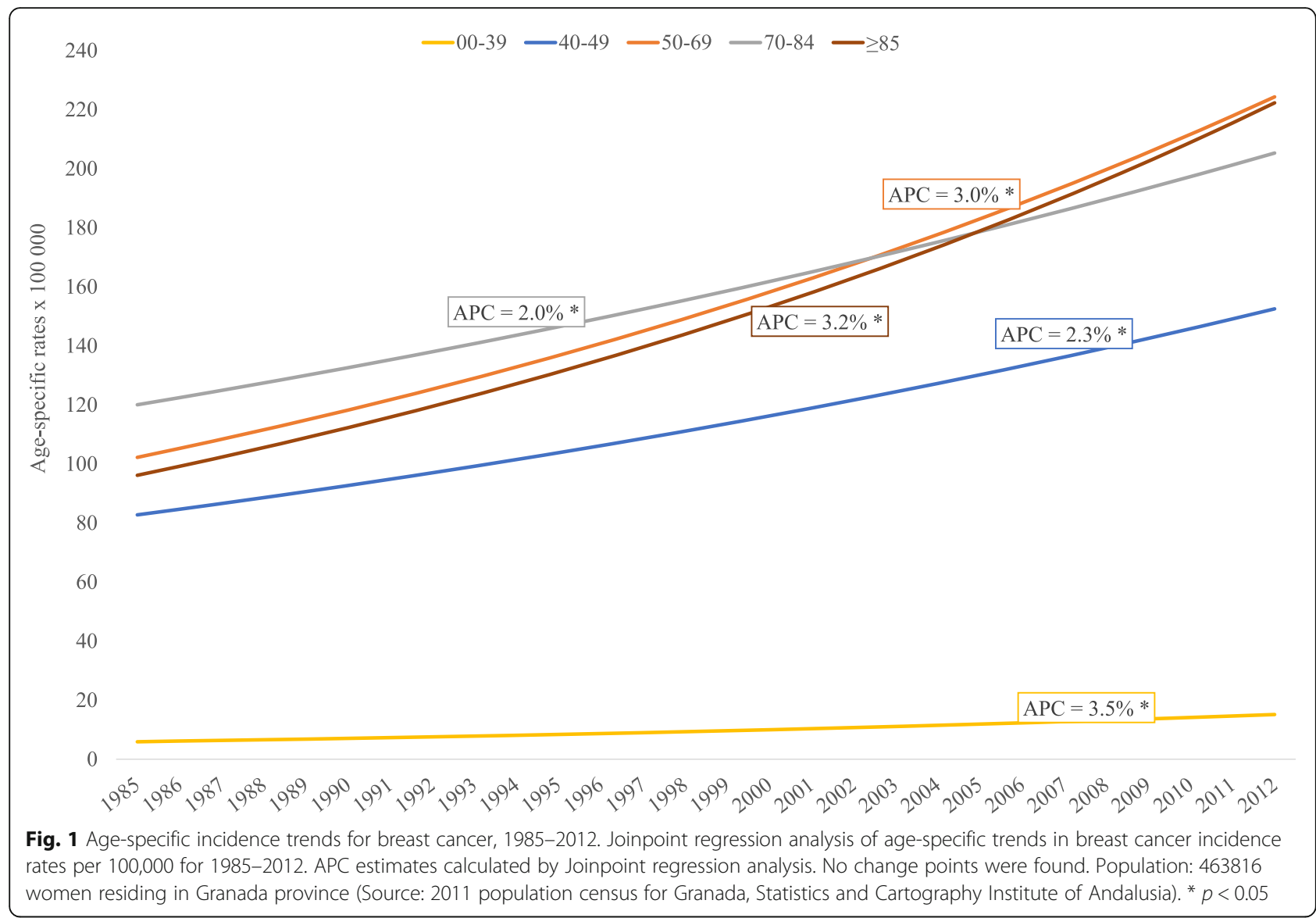

in 2010-2012. For women 70 to 84 years old, survival increased to $70 \%$ until 1995-1999, and then remained stable (Fig. 5). The 85-99 year age group showed a constant increase in 5-year survival from approximately $20 \%$ in 1985-1989 to $60 \%$ in 2010-2012. This group accounted for the smallest number of deaths.

\section{Survival 2000-2012}

Analysis by stage for the final twelve years of our study period disclosed important differences in survival related with disease progression from the moment of diagnosis. Net survival rates at 5 years were $96.6 \%$ in patients whose tumor was diagnosed in stage I, $88.2 \%$ for stage II tumors, and $62.5 \%$ for stage III tumors. The survival rate decreased markedly to $23.3 \%$ in women with stage IV tumors (Table 6).

\section{Discussion}

The results we obtained here with data from the Granada Cancer Registry show a steady increase in breast cancer incidence between 1985 and 2012, with the greatest rise in women younger than 40 years and in the age group targeted for screening: 50-69 years. The decrease in breast cancer mortality and the upward trend in survival support a general improvement in prognosis. At the end of follow-up, women older than 84 years and those with metastatic spread at diagnosis were the groups showing the worst results.

From 1985 to 2012, the incidence of breast cancer in our population has increased, as documented by the APC of $2.5 \%$. A similar increasing trend was observed in Europe, with APCs ranging between 0.8 and 3\% [44]. The introduction of the screening program may have played an important role in this trend, as has been suggested in previous European studies [8, 10, 15-17, 36, $45,46]$.

However, this trend started in our analysis before screening introduction and could also be found in age groups not invited to the program. These findings have been previously interpreted as indicators of the role played by environmental, lifestyle and behavioral exposures $[3,5$, $8,16,23,44,45,47-50]$. Several breast cancer reproductive risk factors such as parity, advanced age at first birth or breast feeding have been highlighted before [51, 52], as well as lifestyle risk factors including alcohol consumption, post-menopausal obesity and sedentarism [53, 54]. Moreover, these finding have also been connected to changes in diagnostic practices, that have increased detection rates $[10,12,16,24,45,48]$, like the increasing use of opportunistic screening [55-57]. 


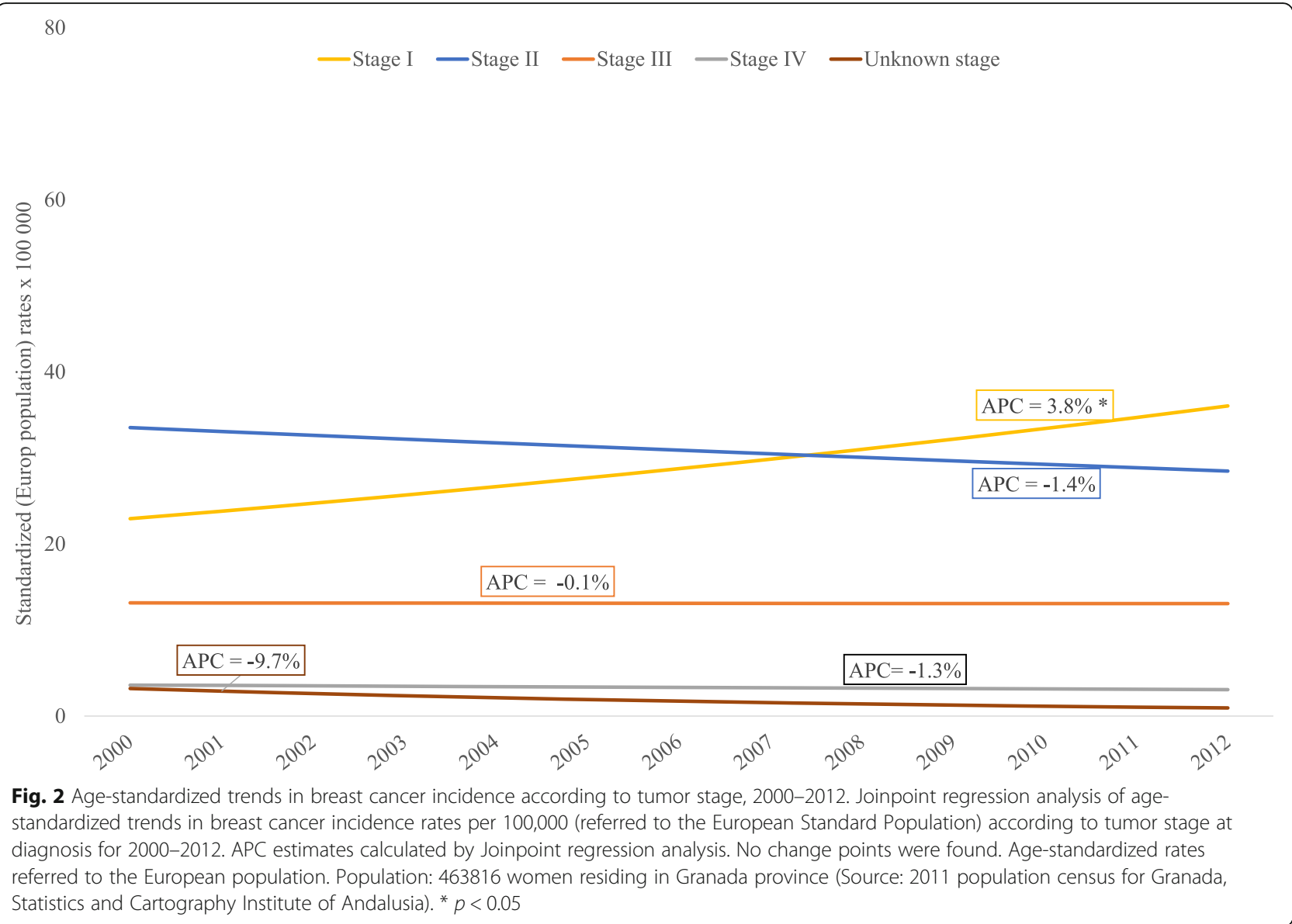

Finally, trying to disentangle the role played by screening program implementation in the increasing incidence from 1985 to 2012 shown in our population, we have performed a comparative analysis of overall and 50-69 year age group incidence trends before and after screening program introduction in our population in 1998. Incidence after 1998 showed a tendency to stabilization in overall analysis, even though trend showed a significant increase for both periods (1985-98 APC 2.9\%, 1998-2012 APC 1.1\%). Analysis of age group 50-69 years showed a positive, though non-significant trend after 1998 (1985-98 APC 2.8\%, 1998-2012 APC 1.3\%). These results suggest the influence of other determinants besides the screening program on the incidence trend shown from 1985 to 2012.

At the beginning of the twenty-first century, a change in this rising trend was seen in many European countries and in the USA. Screening programs initially led to a temporary increase in the incidence, followed by a decrease to pre-screening levels. This phenomenon is related to the diagnosis of silent prevalent cases in the first round and the need to wait until new incident cases occur in the screened population [44]. Moreover, a drop in breast cancer incidence correlated temporarily with the drastic reduction in menopausal hormone therapy in

Table 2 Tumor stage distribution by age group, 2000-2012

\begin{tabular}{lllllll}
\hline Age group (years) & I & II & III & IV & Unknown & Total \\
\hline$<40$ & $108(29.1 \%)$ & $172(46.1 \%)$ & $77(20.6 \%)$ & $12(3.2 \%)$ & $4(1.1 \%)$ & 373 \\
$40-49$ & $360(32.4 \%)$ & $502(45.2 \%)$ & $192(17.3 \%)$ & $36(3.3 \%)$ & $21(1.9 \%)$ & 1111 \\
$50-69$ & $991(44.3 \%)$ & $788(35.3 \%)$ & $312(14.0 \%)$ & $94(4.2 \%)$ & $49(2.2 \%)$ & 2234 \\
$70-84$ & $296(25.1 \%)$ & $485(41.2 \%)$ & $264(22.4 \%)$ & $86(7.3 \%)$ & $47(4.0 \%)$ & 1178 \\
$\geq 85$ & $31(13.9 \%)$ & $65(29.2 \%)$ & $70(31.4 \%)$ & $17(7.6 \%)$ & $40(17.9 \%)$ & 223 \\
Overall & $1792(35.0 \%)$ & $1998(39.0 \%)$ & $911(17.8 \%)$ & $243(4.8 \%)$ & $176(3.4 \%)$ & 5120
\end{tabular}

Number and percentage of breast cancer cases according to tumor stage and age group in 2000-2012. Percentages are rounded. Population: 463816 women residing in Granada province (Source: 2011 population census for Granada, Statistics and Cartography Institute of Andalusia) 
Table 3 Tumor stage distribution by chronological year, 2000-2012

\begin{tabular}{|c|c|c|c|c|c|c|}
\hline Year & I & $\|$ & III & IV & Unknown & Total \\
\hline 2000 & $104(30.6 \%)$ & $144(42.4 \%)$ & $54(15.6 \%)$ & $22(6.5 \%)$ & 17 (5.0\%) & 341 \\
\hline 2001 & $102(29.7 \%)$ & 152 (44.3\%) & 64 (18.7\%) & 15 (4.4\%) & 10 (2.9\%) & 343 \\
\hline 2002 & $111(28.0 \%)$ & $173(43.6 \%)$ & 71 (17.9\%) & $24(6.0 \%)$ & $18(4.5 \%)$ & 397 \\
\hline 2003 & 94 (28.8\%) & 125 (38.4\%) & 70 (21.7\%) & $18(5.6 \%)$ & $18(5.6 \%)$ & 325 \\
\hline 2004 & $115(33.7 \%)$ & 137 (39.9\%) & $62(17.8 \%)$ & 17 (4.4\%) & $14(4.1 \%)$ & 345 \\
\hline 2005 & 119 (34.7\%) & 134 (39.1\%) & 57 (16.6\%) & $23(6.7 \%)$ & $10(2.9 \%)$ & 343 \\
\hline 2006 & $127(32.6 \%)$ & $148(38.0 \%)$ & $87(22.4 \%)$ & 14 (3.6\%) & 13 (3.3\%) & 389 \\
\hline 2007 & $133(32.4 \%)$ & 155 (37.8\%) & 85 (20.7\%) & 20 (4.9\%) & $17(4.1 \%)$ & 410 \\
\hline 2008 & 154 (36.9\%) & 165 (39.8\%) & 70 (16.9\%) & 13 (3.1\%) & 14 (3.4\%) & 416 \\
\hline 2009 & 204 (41.5\%) & 192 (39.1\%) & 69 (13.9\%) & 16 (3.1\%) & 12 (2.5\%) & 493 \\
\hline 2010 & $174(41.8 \%)$ & $134(32.2 \%)$ & 70 (16.9\%) & $18(4.5 \%)$ & $19(4.5 \%)$ & 415 \\
\hline 2011 & $175(37.8 \%)$ & 168 (36.6\%) & 77 (17.0\%) & 31 (6.9\%) & $8(1.7 \%)$ & 459 \\
\hline 2012 & $180(40.5 \%)$ & 171 (38.3\%) & 75 (16.9\%) & 12 (2.9\%) & $6(1.3 \%)$ & 444 \\
\hline Overall & 1792 (35.0\%) & 1998 (39.0\%) & 911 (17.8\%) & $243(4.8 \%)$ & $176(3.4 \%)$ & 5120 \\
\hline
\end{tabular}

Number and percentage of breast cancer cases according to tumor stage and chronological year in 2000-2012. Percentages are rounded. Population: 463816 women residing in Granada province (Source: 2011 population census for Granada, Statistics and Cartography Institute of Andalusia)

many countries $[8,15,58]$ after the results of the WHI study were published [59]. These changes were observed in overall analyses and in postmenopausal women $[8,15]$. However, none of these changes was found in our analysis of overall incidence, or in the 50-69 year age group.
A screening program in our population was introduced in 1998, and the whole target population was invited for the fifth round in 2002. In Granada the screening participation rate has been higher than $70 \%$ since 1999, and the median detection rate for the entire

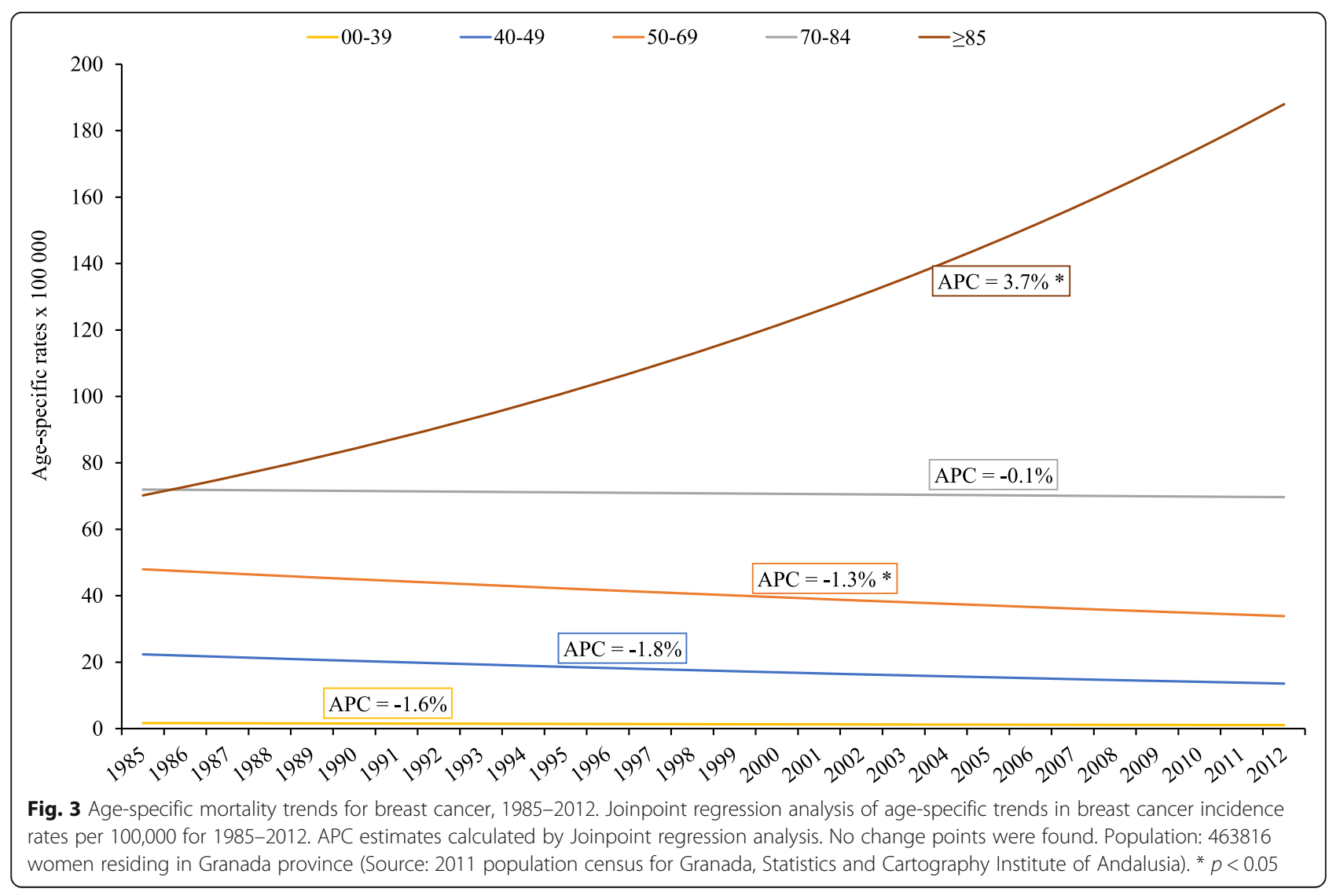


Table 4 Age-specific mortality trends for breast cancer in the female population in Granada province, 2000-2012

\begin{tabular}{llll}
\hline & $\mathrm{N}$ & $\mathrm{APC}$ & $95 \% \mathrm{Cl}$ \\
\hline Total & 1246 & -0.7 & $-2.3-0.9$ \\
Age group (years) & & & \\
$\quad 00-39$ & 35 & -4.2 & $-12.0-4.2$ \\
$40-49$ & 132 & 4.2 & $-1.8-10.4$ \\
$50-69$ & 433 & -2.7 & $-5.3-0.0$ \\
$70-84$ & 466 & -1.2 & $-2.6-2.7$ \\
85 and over & 180 & 1.8 & $-2.3-6.1$
\end{tabular}

APC estimates calculated by Joinpoint regression analysis of age-specific mortality rates, for 2000-2012. Population: 463816 women residing in Granada province (Source: 2011 population census for Granada, Statistics and Cartography Institute of Andalusia). APC: annual percentage change

study period was $3.5 \%$. These surrogate indicators confirm the good performance of screening in our setting, according to the European Guidelines for Quality Assurance in Breast Cancer Screening and Diagnosis [60]. In light of this finding, the absence of changes in incidence trends seems not to be related to a reduced or delayed implementation of the program.

A previous study of the population analyzed here showed a temporary rise in incidence until 2004, similar to reports from other regions in Spain and consistent with the diagnosis of prevalent cases [9]. The longer follow-up period after screening introduction presented in our paper reduced the likelihood of finding smaller temporal trend changes in the Joinpoint analysis and could explain the absence of changes in incidence trend in our population. However, differences in age groups definition between both analyses, due to changes in the age range included in the Andalusian screening program, could also have played a role.

Some specific characteristics of our population may partially explain the absence of changes in temporal trends.

Table 5 Trends in observed 5-year survival and age-

standardized net survival in women with breast cancer

\begin{tabular}{lllllllll}
\hline Period & $n$ & \multicolumn{3}{c}{ Observed survival } & & \multicolumn{3}{c}{ Net survival (age-standardized) } \\
& & OS & $95 \% \mathrm{Cl}$ & & & NS & $95 \% \mathrm{Cl}$ & \\
\hline $1985-1989$ & 844 & 63.9 & 60.5 & 67.0 & & 67.5 & 61.8 & 72.5 \\
1990-1994 & 1087 & 67.5 & 64.6 & 70.2 & & 69.6 & 64.7 & 73.9 \\
$1995-1999$ & 1344 & 73.7 & 71.3 & 76.0 & 76.4 & 72.4 & 79.8 \\
2000-2004 & 1721 & 77.0 & 75.0 & 79.0 & 78.9 & 75.7 & 81.8 \\
2005-2009 & 2030 & 80.0 & 78.2 & 81.7 & 82.1 & 79.0 & 84.7 \\
2010-2012 & 1791 & 81.0 & 78.8 & 83.1 & 83.7 & 79.8 & 86.8 \\
\hline
\end{tabular}

aperiod analysis instead of cohort analysis was used

Estimates for observed survival calculated with the Kaplan-Meyer method, and for net survival calculated with the Pohar-Perme method (cohort analysis) in 5-year periods from 1985 to 2012 and in the 3-year period from 2010 to 2012. Age-standardized rates referred to the European population. Population: 463816 women residing in Granada province (Source: 2011 population census for Granada, Statistics and Cartography Institute of Andalusia). OS: observed survival; NS: net survival
During the study period, hormonal replacement therapy was prescribed to a lesser extent in Spain compared to other European countries [11, 61], so the increase in incidence during the 1990s and later decrease during the beginning of the 2000s due to the usual prescribing patterns were probably not as large as in other countries. Our setting (southern Spain) is at a relatively low socioeconomic level within the European Union, and this factor is known to be associated with a lower incidence [1]. This circumstance may mean a smaller number of silent prevalent cases at the beginning of the screening program, and hence a less dramatic fall after screening began. Finally, we should consider the effect of opportunistic screening as a source of potential bias, as previously described by international organisms [62]. This diagnostic practice shows high detection rates, especially for early stage and in-situ cancer [63], so it could have reduced the amount of prevalent cases that otherwise would have been detected in the first screening round [10]. No information is available regarding the extent of opportunistic screening in Granada province before or during our study period. However, this practice has been proved to be common in other countries [55], as well as in other regions of Spain before screening program introduction $[56,57]$, and its effect over incidence trends have been considered in previous studies $[45,64]$.

To better understand the effects of population-based screening, we undertook an analysis by tumor stage at the time of diagnosis for the period from 2000 to 2012 . As expected, a statistically significant increase was observed in stage I tumors at diagnosis. The age distribution confirmed that this increase occurred mainly in the age group targeted for screening (50-69 years) - a trend consistent with earlier diagnosis due to screening. However, the absence of a parallel decrease in advanced-stage tumors in our distribution, has been attributed to the non-progressive nature of a large proportion of tumors potentially detectable by the program, and does not support this earlier diagnosis [17]. A favorable stage distribution due to screening is suggested by the lower proportion of stage III tumors in the screened age group (50-69 years old), but no decreasing trend was seen for this group in the Joinpoint analysis.

The decrease we observed in breast cancer mortality was noted throughout the whole period analyzed here. In Spain there has been a generalized decrease in mortality since 1992, although there is some variability among geographical regions [65]. This downward trend started in our cohort before the screening program was implemented, as in almost every region in Spain [65] and in other European countries [23]. Hormonal treatments and new polychemotherapy schemes were also introduced during the 1990s, and together with the increased use of effective radiotherapy regimens, 


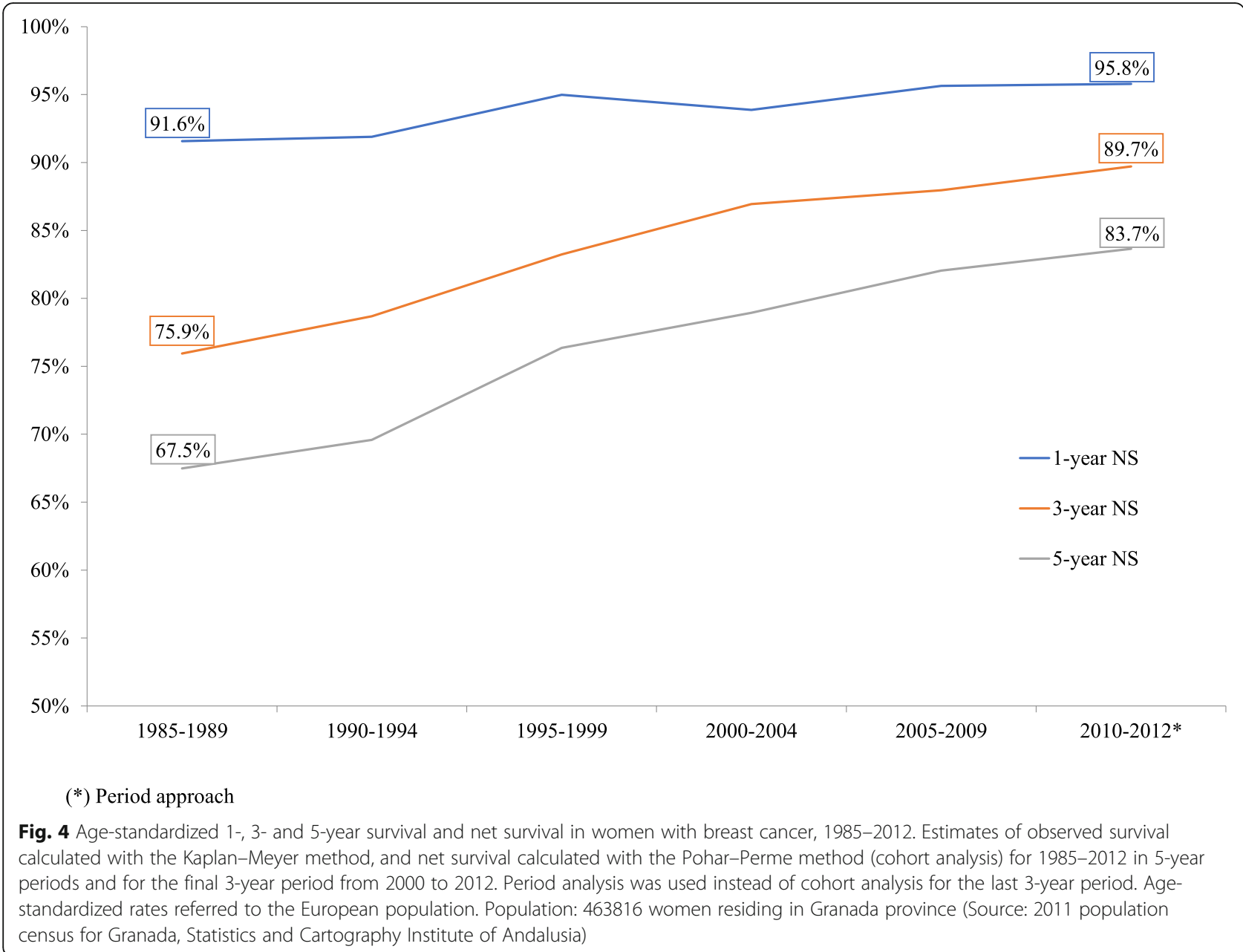

probably played an important role in this trend [24, 36, 45, 66-68]. Metanalysis of the effectiveness of clinical trials with adjuvant treatments showed a marked reduction in breast cancer mortality, and in some cases, in all-cause mortality [31, 32].

The favorable evolution of survival trends is consistent with findings reported for other European countries [29] and the USA [27]; these trends correlate with tumor stage at diagnosis [69]. In our analysis, we found an increase in stage I tumors during the 2000-2012 period. Despite this favorable trend, survival did not increase in the 70-84 year group or in the subgroup with metastatic tumors at diagnosis. Adjuvant treatment, one of the factors responsible for this trend, is less effective for this stage and age group [70]. Women older than 70 years also have more comorbidities, and breast-conserving surgery plus adjuvant therapy are used to a lesser extent; both of these factors are related to decreased survival [71]. In the 85-99 year age group survival increased markedly from $23 \%$ in $1985-1989$ to $62 \%$ in $2010-2012$. However, the small number of deaths in this age group precludes any conclusions regarding this particular subgroup.
Mortality in women older than 70 years in Europe has shown an increasing trend or a smaller decrease than in younger age groups [19]. In our results, mortality increased in this age group (data not shown). This trend was also found for women older than 84 years in a separate analysis. In the 7084 year and $>84$ year age groups the proportion of metastatic tumors was larger than in other age groups (Table 2). Both older age and a greater proportion of metastatic tumors are important factors in the response to treatment. Moreover, women older than 70 years are less likely to receive standard treatment [72].

In our analysis of women younger than 40 years, the incidence trend (APC 3.6\%) was larger than the trend reported for this age group in other European countries: the European median APC is $1.2 \%$ [13]. There appear to be no clear correlations between trends in this age group and known risk factors [13]. In younger women at least one earlier study found that factors related with tumor biology were associated with a greater risk of death and a worse prognosis [14]. 


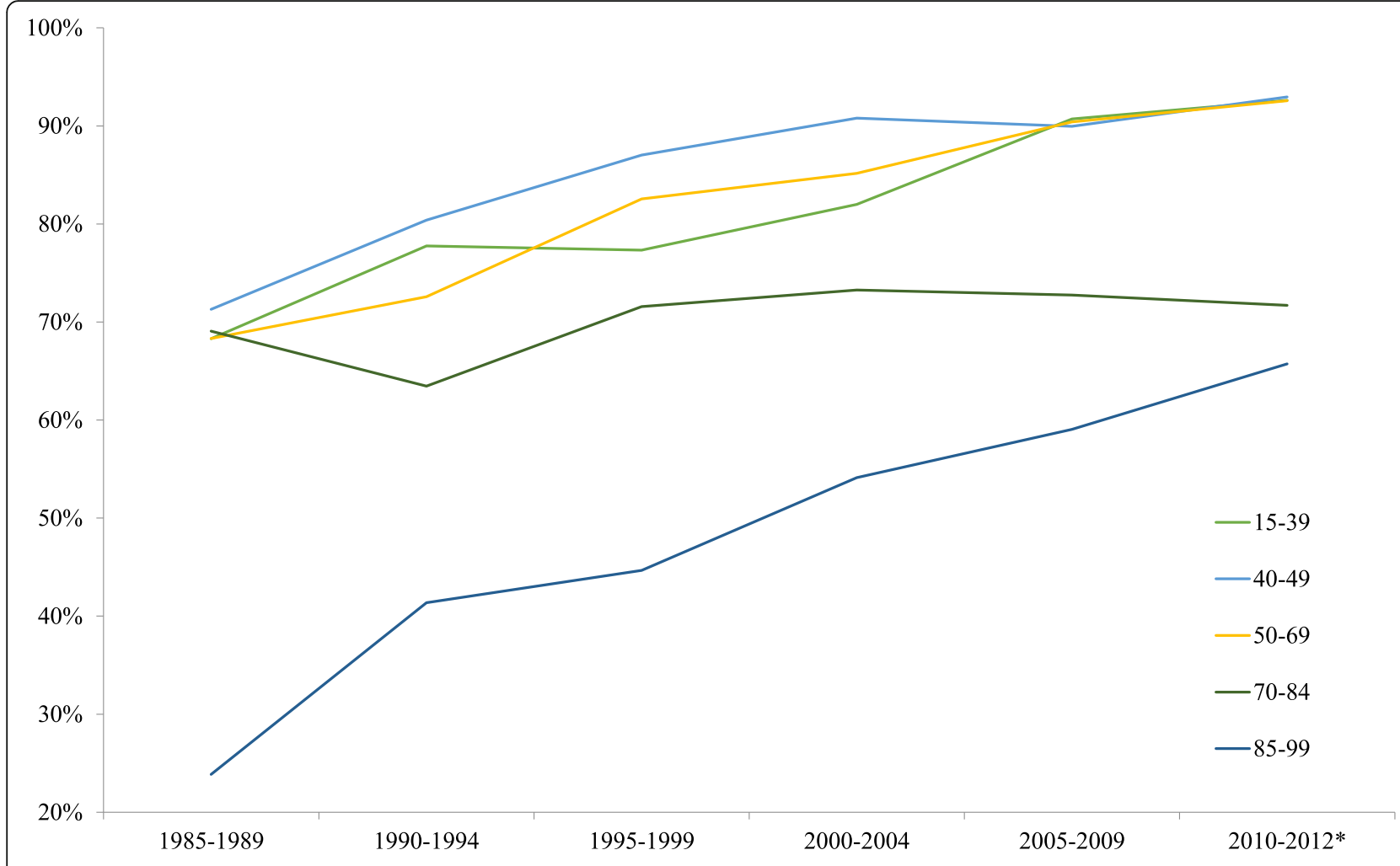

$(*)$ Period approach

Fig. 5 Five-year age-specific net survival in women with breast cancer, 1985-2012. Estimates of net survival calculated with the Pohar-Perme method (cohort analysis) for 1985-2012 in 5-year periods and for the final 3-year period from 2000 to 2012. Period analysis was used instead of cohort analysis for the last 3-year period. Population: 463816 women residing in Granada province (Source: 2011 population census for Granada, Statistics and Cartography Institute of Andalusia)

Some authors have noted that changes in diagnostic patterns with the increased use of mammography and ultrasonography, along with wider access to MRI, are likely to be important factors in the reported increases in incidence among younger women [20]. In our study, more than $75 \%$ of tumors were diagnosed at stages I-II, and survival rates were similar to those in other age groups. These findings are consistent with the concurrent

Table 6 Age-standardized net survival according to stage in women with breast cancer, 2000-2012

\begin{tabular}{llll}
\hline Stage & 1-year NS & 3-year NS & 5-year NS \\
\hline I & 99.9 & 98.3 & 96.6 \\
II & 99.7 & 95.1 & 88.2 \\
III & 91.4 & 75.3 & 62.5 \\
IV & 60.0 & 35.0 & 23.3 \\
Unknown & 92.3 & 77.4 & 75.4 \\
\hline
\end{tabular}

Estimates for net survival calculated with the Pohar-Perme method (cohort analysis), according to tumor stage at the time of diagnosis (TNM 7th edition), 2000-2012

Age-standardized rates referred to the European population. Population: 463816 women residing in Granada province (Source: 2011 population census for Granada, Statistics and Cartography Institute of Andalusia). NS: net survival use of opportunistic screening in parallel with populationbased screening programs. The influence of opportunistic screening was demonstrated in Barcelona, where $27.1 \%$ of women younger than 40 years received routine screening with mammography before a population-based program was introduced [57]. Moreover, 23.5\% of women younger than 45 years reported having a mammography examination in 2014 [73], and 5\% of this age group had visited a gynecologist for reasons other than pregnancy in the previous year [74]. Unfortunately, the lack of information regarding hormonal receptors and HER2 overexpression prevented us from analyzing these trends according to pathologic subtypes.

The decrease in overall mortality in Europe is reportedly greater in women younger than 50 years [19], and international studies confirm greater mortality with advancing age [5]. In our cohort, the $0-50$ year age group showed a stable trend, in contrast to the decrease observed for women 50 to 69 years old (data not shown). In a differential analysis of the 40-49 year age group, we also found no statistically significant decrease. Previous research in Spain, however, reported a decrease in mortality among 
women younger than 40 years [75], so the difference between studies may reflect regional differences in incidence. However, caution should be used when interpreting these results given that the number of deaths in this age range is low.

The results of our analysis are strengthened by the inclusion of the most recent available data from the Granada population-based cancer registry, which has been in operation for 25 years and holds data for approximately 9000 registered cases of invasive breast cancer. We used appropriate statistical methods to detect trend changes and to calculated net survival rates. The high quality of the data was ensured by quality control measures, e.g. microscopic confirmation of the diagnosis in $96 \%$ of all registered cases, only $1.8 \%$ of which recorded the diagnosis based only on information from the death certificate.

Nevertheless, several limitations should be considered when interpreting our findings. The Granada Cancer Registry limits its target population to the provincial level, with a total population of approximately 1 million people. Population-specific characteristics need to be considered, along with the low number of events for some analyses. The absence of consistent information about risk factors prevalence in our population has not permitted us to present a direct interpretation of their role in time trends. Because of the mentioned factors, the external validity of our results may be limited, and the statistical power of some analyses was insufficient to reach definitive conclusions. In addition, lack of stage at diagnosis data before year 2000 refrained us from performing Joinpoint regression of breast cancer incidence according to stage for the whole period. Despite these limitations, this study provides population-based results for a long period of study, documents for the first time the evolution of breast cancer incidence according to stage at the time of diagnosis and provides some clues regarding the effect of screening on this important prognostic variable.

\section{Conclusions}

In conclusion, the data from a population-based cancer registry in southern Spain show an increasing trend in breast cancer incidence from 1985 to 2012. The increases were greatest in the 0 to 49 and 50 to 69 years age groups. No change points in incidence trends were found in Joinpoint regression analysis for this period. This evolution is consistent with the spread of risk factors and the rise in diagnostic pressure $[3,8,16,23,36$, $44,45,47,55,76]$. Further analyses of incidence trends determinants should be carried out, especially in young women, for designing future prevention strategies. We did not observe the previously turning point in incidence at the beginning of the twenty-first century in our country $[8-10,77]$ and, as we have already discussed, several causes may explain this difference.
Incidence trends by stage at diagnosis for the 20002012 period show an increase in stage I tumors. The absence of an equivalent decrease in advanced stage tumors suggests that at least a proportion of the tumors detected thanks to screening are non-progressive, raising doubts about screening effectiveness. However, the reduced proportion of stage III tumors in the 50-69 year age group points to a favorable shift in stage distribution. It should also be considered that tumors identified as metastatic at diagnosis represent a more aggressive type of breast cancer that may not benefit from mammographic screening, neither from advances in treatment. Therefore, it is possible that specific prevention strategies for metastatic breast cancer should be developed.

Mortality decreased slightly during the 1985-2012 period, although analysis by age group showed that this trend was statistically significant only in women aged 50-69 years. Although this is the age group the screening program is targeted to, the absence of any change in trend after screening was introduced, and the lack of a clear decrease in incidence during the 2000-2012 period, do not support a substantial beneficial effect.

The trend in survival of breast cancer in our setting has evolved favorably except in the 70-84 year age group, in which women more frequently receive non-standard treatments, and in which the percentage of stage I tumors characterized by their better response to treatments - was lower than in other age groups.

\section{Abbreviations}

APC: annual percentage change; ASR-E: age-standardized rate referred to European population; ASR-W: age-standardized rate referred to world population; CIFC: Cancer in Five Continents; ENCR: European Net of Cancer Registries; REDECAN: Spanish Network of Cancer Registries; WHI: Women Health Initiative

\section{Acknowledgements}

We thank the Granada Cancer Registry staff for extracting data from raw data sources and generating the dataset from the registry, and K. Shashok for improving the use of English in the manuscript.

\section{Funding}

This study was supported by a grant from the Acción Estratégica en Salud plan for the High Resolution Project on Prognosis and Care of Cancer Patients (No. AC14/00036) awarded by the Spanish Ministry of Economy and Competitiveness and co-funded by the European Regional Development Fund (ERDF). The funding had no role in the design of the study and collection, analysis, and interpretation of data and in writing the manuscript.

\section{Availability of data and materials}

The anonymized datasets used and/or analyzed for incidence and survival analysis in this study are available from the corresponding author on reasonable request.

The data that support the mortality findings of this study are available from the National Death Index but restrictions apply to the availability of these data, which were used under license and are not publicly available. However, the data are available from the authors upon reasonable request and with the permission of the Ministry of Health, Social Services and Equality. Granada Cancer Registry is a member of the European Net of Cancer Registries (ENCR) and the Spanish Network of Cancer Registries (REDECAN). It collaborates in, among others, the EUROCARE and CONCORD studies. 


\section{Authors' contributions}

JAB participated in the conception and design of the study, collaborated in data analysis and interpretation, and was directly involved in drafting the manuscript. EP and MR-B analyzed the data for incidence and mortality trends, and for observed and net survival. Both participated in revising the manuscript. MP, RDM, LA and ES-C made significant contributions to data interpretation and manuscript revision by providing divergent and multidisciplinary points of view based on epidemiology, statistics and clinical practice (primary health care and oncology).

MJS participated in the conception and design of the study, in data interpretation, and in drafting and revising the manuscript. All authors read and approved the final manuscript.

\section{Authors' information}

This paper is part of the doctoral thesis prepared by the first and corresponding author in the Inter-University Health Sciences Doctoral Program offered jointly by the University of Seville, the University of Jaen and the Andalusian School of Public Health.

\section{Ethics approval and consent to participate}

The dataset of the population-based cancer registry is registered as stipulated by law according to the Spanish Data Protection Agency (Agencia Española de Protección de Datos. https://www.agpd.es). All data collected in the database for incidence and survival analysis were anonymous, and no ethical approval was required.

Mortality data were obtained from public database of the National Institute of Statistics, and were previously anonymized, so no ethical approval was required.

\section{Consent for publication}

Not applicable.

\section{Competing interests}

The authors declare that they have no competing interests.

\section{Publisher's Note}

Springer Nature remains neutral with regard to jurisdictional claims in published maps and institutional affiliations.

\section{Author details}

'Departamento de Urgencias y Emergencias, Área de Gestión Sanitaria Noreste, Hospital Regional de Baza, Carretera de Murcia s/n, 18800 Baza, Spain. ${ }^{2}$ Escuela Andaluza de Salud Pública, Instituto de Investigación Biosanitaria ibs, Hospitales Universitarios de Granada/Universidad de Granada, Granada, Spain. ${ }^{3}$ Public Health and Epidemiology CIBER Network (CIBERESP), Madrid, Spain. ${ }^{4}$ Environmental and Cancer Epidemiology Department, National Center of Epidemiology - Instituto de Salud Carlos III, Madrid, Spain. ${ }^{5}$ Department of Radiotherapy and Oncology, Virgen de las Nieves University Hospital, Granada, Spain. ${ }^{6}$ Centro de Salud La Chana, Área de Gestión Sanitaria Granada-Metropolitano, Granada, Spain. ${ }^{7}$ Department of Epidemiology and Public Health, University of Granada, Granada, Spain.

Received: 22 May 2017 Accepted: 19 July 2018

Published online: 02 August 2018

\section{References}

1. Bray F, Jemal A, Grey N, Ferlay J, Forman D. Global cancer transitions according to the human development index (2008-2030): a populationbased study. Lancet Oncol. 2012;13:790-801.

2. Fitzmaurice C, Allen C, Barber RM, Barregard L, Bhutta ZA, Brenner $H$, et al. Global, regional, and National Cancer Incidence, mortality, years of life lost, years lived with disability, and disability-adjusted life-years for 32 Cancer groups, 1990 to 2015. JAMA Oncol. 2017;3:524.

3. Althuis MD, Dozier JM, Anderson WF, Devesa SS. Brinton L a. Global trends in breast cancer incidence and mortality 1973-1997. Int J Epidemiol. 2005; 34:405-12.

4. Galceran J, Ameijide A, Carulla M, Mateos A, Quirós J, Rojas M, et al. Cancer incidence in Spain, 2015. Clin Transl Oncol. 2017:19:799-825.

5. Héry C, Ferlay J, Boniol M, Autier P. Quantification of changes in breast cancer incidence and mortality since 1990 in 35 countries with Caucasianmajority populations. Ann Oncol. 2008;19:1187-94.
6. Hankinson SE, Colditz GA, Willett WC. Towards an integrated model for breast cancer etiology: the lifelong interplay of genes, lifestyle, and hormones. Breast Cancer Res. 2004;6:213-8.

7. Lacey J, Devesa S, Brinton L. Recent trends in breast cancer incidence and mortality. Environ Mol Mutagen 2002;88:82-8.

8. Glass AG, Lacey JV, Carreon JD, Hoover RN. Breast cancer incidence, 1980-2006: combined roles of menopausal hormone therapy, screening mammography, and estrogen receptor status. J Natl Cancer Inst. 2007;99:1152-61.

9. Pollán M, Pastor-Barriuso R, Ardanaz E, Arguelles M, Martos C, Galceran J, et al. Recent changes in breast cancer incidence in Spain, 1980-2004. J Natl Cancer Inst. 2009;101:1584-91.

10. Pollán M, Michelena MJ, Ardanaz E, Izquierdo A, Sánchez-Pérez MJ, Torrella A, et al. Breast cancer incidence in Spain before, during and after the implementation of screening programmes. Ann. Oncologia. 2010;21:97-102.

11. Costas L, Sequera V-G, Quesada P, Altzibar JM, Lope V, Perez-Gomez $B$, et al. Hormonal contraception and postmenopausal hormone therapy in Spain: time trends and patterns of use. Menopause-the J. 2015;22:1138-46

12. Colonna M, Delafosse $P$, Uhry Z, Poncet F, Arveux P, Molinie F, et al. Is breast cancer incidence increasing among young women? An analysis of the trend in France for the period 1983-2002. Breast. 2008;17:289-92.

13. Leclère B, Molinie F, Tretarre B, Stracci F, Daubisse-Marliac L, Colonna M, et al. Trends in incidence of breast cancer among women under 40 in seven European countries: a GRELL cooperative study. Cancer Epidemiol. 2013;37: 544-9.

14. Pollán M. Epidemiology of breast cancer in young women. Breast Cancer Res Treat. 2010;123:3-6.

15. Daubisse-Marliac L, Delafosse P, Boitard JB, Poncet F, Grosclaude P, Colonna M. Breast cancer incidence and time trend in France from 1990 to 2007: a population-based study from two French cancer registries. Ann Oncol. 2011; 22:329-34.

16. Louwman WJ, Voogd a. C, Van Dijck J a a M, Nieuwenhuijzen G a P, Ribot J, Pruijt JFM, et al. On the rising trends of incidence and prognosis for breast cancer patients diagnosed 1975-2004: A long-term population-based study in southeastern Netherlands. Cancer Causes Control. 2008;19:97-106.

17. Welch HG, Prorok PC, O'Malley AJ, Kramer BS. Breast-Cancer tumor size, Overdiagnosis, and mammography screening effectiveness. N Engl J Med. 2016;375:1438-47.

18. Bleyer A, Welch HG. Effect of three decades of screening mammography on breast-Cancer incidence. N Engl J Med. 2012;367:1998-2005.

19. Autier $\mathrm{P}$, Boniol M, LaVecchia C. Disparities in breast cancer mortality trends between 30 European countries: retrospective trend analysis of WHO mortality database. BMJ. 2010;341:c3620.

20. Levi F, Bosetti C, Lucchini F, Negri E, La Vecchia C. Monitoring the decrease in breast cancer mortality in Europe. Eur J Cancer Prev. 2005;14:497-502.

21. Bosetti C, Bertuccio P, Levi F, Chatenoud L, Negri E, La Vecchia C. The decline in breast cancer mortality in Europe: an update (to 2009). Breast. 2012;21:77-82.

22. IARC. WHO Cancer Mortality Database. http://www-dep.iarc.fr/WHOdb/ WHOdb.htm. Accessed 20 Jan 2017.

23. Autier $\mathrm{P}$, Boniol M, Gavin A, Vatten LJ. Breast cancer mortality in neighbouring European countries with different levels of screening but similar access to treatment: trend analysis of WHO mortality database. BMJ. 2011:343:d4411.

24. Jatoi I, Miller AB. Why is breast-cancer mortality declining? Lancet Oncol. 2003:4:251-4.

25. Sant M, Francisci S, Capocaccia R, Verdecchia A, Allemani C, Berrino F. Time trends of breast cancer survival in Europe in relation to incidence and mortality. Int J Cancer. 2006;119:2417-22.

26. Allemani C, Sant M, Weir HK, Richardson LC, Baili P, Storm H, et al. Breast cancer survival in the US and Europe: a CONCORD high-resolution study. Int J Cancer. 2013;132:1170-81.

27. Allemani C, Weir HK, Carreira H, Harewood R, Spika D, Wang X-S, et al. Global surveillance of cancer survival 1995-2009: analysis of individual data for 25,676,887 patients from 279 population-based registries in 67 countries (CONCORD-2). Lancet. 2015;385:977-1010.

28. Sant M, Chirlaque Lopez MD, Agresti R, Sánchez Pérez MJ, Holleczek B, Bielska-Lasota $M$, et al. Survival of women with cancers of breast and genital organs in Europe 1999-2007: results of the EUROCARE-5 study. Eur J Cancer. 2015;51:2191-205 
29. De Angelis R, Sant M, Coleman MP, Francisci S, Baili P, Pierannunzio D, et al. Cancer survival in Europe 1999-2007 by country and age: results of EUROCARE--5-a population-based study. Lancet Oncol. 2014;15:23-34.

30. Gotzsche PC, Jorgensen KJ. Screening for breast cancer with mammography. Cochrane Database Syst Rev. 2013; https://doi.org/10.1002/ 14651858.CD001877.pub5.

31. Early Breast Cancer Trialists' Collaborative Group (EBCTCG). Effects of chemotherapy and hormonal therapy for early breast cancer on recurrence and 15-year survival: an overview of the randomised trials. Lancet. 2005;365: 1687-717.

32. Early Breast Cancer Trialists' Collaborative Group (EBCTCG), Darby S, McGale P, Correa C, Taylor C, Arriagada R, et al. Effect of radiotherapy after breastconserving surgery on 10-year recurrence and 15-year breast cancer death: meta-analysis of individual patient data for 10,801 women in 17 randomised trials. Lancet. 2011;378:1707-16.

33. Crocetti E, Buzzoni C, Falcini F, Cortesi L, De Lisi V, Ferretti S, et al. Disentangling the roles of mammographic screening and HRT in recent breast cancer incidence trends in Italy by analyses based on calendar time and time since screening activation. Breast Journal. 2010;16(4):350-5. https://doi.org/10.1111/j.1524-4741.2010.00928.x.

34. Kerlikowske K, Miglioretti DL, Buist DSM, Walker R, Carney P. Declines in invasive breast cancer and use of postmenopausal hormone therapy in a screening mammography population. J Natl Cancer Inst. 2007:99:1335-9.

35. World Health Organization (WHO). International statistical classification of diseases and related health problems, 10th Revision. http://apps.who.int/ classifications/icd10/browse/2016/en. Accessed 15 Dec 2016.

36. Autier P, Boniol M, Koechlin A, Pizot C, Boniol M. Effectiveness of and overdiagnosis from mammography screening in the Netherlands: population based study. BMJ. 2017;359:j5224.

37. Autier P, Boniol M. Pitfalls in using case-control studies for the evaluation of the effectiveness of breast screening programmes. Eur J Cancer Prev. 2013; 22:391-7.

38. Quaglia A, Tavilla A, Shack L, Brenner H, Janssen-Heijnen M, Allemani C, et al. The cancer survival gap between elderly and middle-aged patients in Europe is widening. Eur J Cancer. 2009:45:1006-16.

39. SBE, Byrd DR, Compton CC, AG F, Greene FL, A T, editors. AJCC Cancer staging manual. 7th ed. France: Springer; 2010.

40. Kim HJ, Fay MP, Feuer EJ, Midthune DN. Permutation tests for joinpoint regression with applications to cancer rates. Stat Med. 2000;19:335.

41. Perme MP, Stare J, Estève J. On estimation in relative survival. Biometrics. 2012;68:113-20

42. Brenner H, Gefeller O, Hakulinen T. Period analysis for "up-to-date" cancer survival data: theory, empirical evaluation, computational realisation and applications. Eur J Cancer. 2004;40:326-35.

43. Dickman PW, Lambert PC, Coviello E, Rutherford MJ. Estimating net survival in population-based cancer studies. Int J Cancer. 2013;133:519-21.

44. Botha JL, Bray F, Sankila R, Parkin DM. Breast cancer incidence and mortality trends in 16 European countries. Eur J Cancer. 2003;39:1718-29.

45. Molinié F, Vanier A, Woronoff AS, Guizard AV, Delafosse $P$, Velten $M$, et al. Trends in breast cancer incidence and mortality in France 1990-2008. Breast Cancer Res Treat. 2014;147:167-75.

46. Héry C, Ferlay J, Boniol M, Autier P. Changes in breast cancer incidence and mortality in middle-aged and elderly women in 28 countries with Caucasian majority populations. Ann Oncol. 2008;19:1009-18.

47. Youlden DR, Cramb SM, Dunn NA M, Muller JM, Pyke CM, Baade PD. The descriptive epidemiology of female breast cancer: an international comparison of screening, incidence, survival and mortality. Cancer Epidemiol. 2012;36:237-48

48. Ondrusova M, Muzik J, Durdik S, Ondrus D. Trends in the development of the epidemiology of breast cancer in the Slovak and Czech Republic with reference to applied screening and international comparisons. Neoplasma. 2012;59(1):70-8

49. Viel J-F, Rymzhanova R, Fournier E, Danzon A. Trends in invasive breast cancer incidence among French women not exposed to organized mammography screening: an age-period-cohort analysis. Cancer Epidemiol. 2011;35:521-5.

50. Weedon-Fekjær H, Romundstad PR, Vatten LJ. Modern mammography screening and breast cancer mortality: population study. BMJ. 2014; 348:g3701.

51. Lambertini M, Santoro L, Del Mastro L, Nguyen B, Livraghi L, Ugolini D, et al. Reproductive behaviors and risk of developing breast cancer according to tumor subtype: a systematic review and meta-analysis of epidemiological studies. Cancer Treat Rev. 2016;49:65-76.

52. Anderson KN, Schwab RB, Martinez ME. Reproductive risk factors and breast cancer subtypes: a review of the, literature. Breast Cancer Res Treat. 2014; 144:1-10.

53. Stewart BW. Wild CP (eds.). World Cancer report 2014. International Agency for Research on Cancer: Lyon; 2014.

54. World Cancer Research Fund International /American Institute for Cancer Research. Continuous Update Project Report: Diet, nutrition, physical activity and breast cancer. 2017. http://wcrf.org/breast-cancer-2017/. Accesed 15 May 2018.

55. Heikkinen S, Miettinen J, Koskenvuo M, Huovinen R, Pitkäniemi J, Sarkeala T, et al. Proportion of women with self-reported opportunistic mammography before organized screening. Acta Oncol. 2016;55:865-9.

56. Puig-Vives M, Pollan M, Rue M, Osca-Gelis G, Saez M, Izquierdo A, et al. Rapid increase in incidence of breast ductal carcinoma in situ in Girona, Spain 1983-2007. Breast. 2012;21:646-51.

57. Rohlfs I, Borrell C, Plasència A, Pasarín I. Social inequalities and realisation of opportunistic screening mammographies in Barcelona (Spain). J Epidemiol Community Health. 1998;52(3):205-6.

58. Ravdin $\mathrm{P}$, Cronin K. The decrease in breast-cancer incidence in 2003 in the United States. N Engl J Med. 2007:1670-4.

59. Rossouw JE, Anderson GL, Prentice RL, LaCroix AZ, Kooperberg C, Stefanick $M L$, et al. Risks and benefits of estrogen plus progestin in healthy postmenopausal women: principal results from the Women's health initiative randomized controlled trial. JAMA. 2002;288:321-33.

60. Perry N, Broeders M, Wolf C, Törnberg S, Holland R, Von Karsa L, editors. European guidelines for quality assurance in breast Cancer screening and diagnosis. 4th ed. Luxembourg: Office for Official Publications of the European Communities; 2006.

61. Benet Rodríguez M, Carvajal García-Pando A, García Del Pozo J, Alvarez Requejo A, Vega AT. Terapia Hormonal Sustitutiva en España. Med Clin. 2002;119:4-8.

62. Nelson HD, Cantor A, Humphrey L, Fu R, Pappas M, Daeges M, et al. Screening for Breast Cancer: A Systematic Review to Update the 2009 U.S. Preventive Services Task Force Recommendation. Evid Synth. 2016;124.

63. Teh Y-C, Tan G-H, Taib NA, Rahmat K, Westerhout CJ, Fadzli F, et al. Opportunistic mammography screening provides effective detection rates in a limited resource healthcare system. BMC Cancer. 2015;15:405.

64. Lynge $\mathrm{E}$, Braaten $\mathrm{T}$, Njor SH, Olsen AH, Kumle M, Waaseth $\mathrm{M}$, et al. Mammography activity in Norway 1983 to 2008. Acta Oncol. 2011;50: 1062-7.

65. Lancis CV, Martínez-sánchez JM, Mateos M. Mortalidad por cáncer de mama: evolución en España y sus comunidades autónomas durante el periodo 1980-2005. Rev Esp Salud Publica. 2010;84(1):53-92010;53-9.

66. Tabar L, Yen M-F, Vitak B, Chen H-HT, Smith RA, Duffy SW. Mammography service screening and mortality in breast cancer patients: 20-year follow-up before and after introduction of screening. Lancet. 2003;361:1405-10.

67. Birnbaum J, Gadi VK, Markowitz E, Etzioni R. The effect of treatment advances on the mortality results of breast Cancer screening trials: a microsimulation model. Ann Intern Med. 2016;164:236-43.

68. Koleva-Kolarova RG, Zhan Z, Greuter MJW, Feenstra TL, De Bock GH, Moss SM, et al. Simulation models in population breast cancer screening: a systematic review. Breast. 2015:24:354-63.

69. Sant M, Allemani C, Capocaccia R, Hakulinen T, Aareleid T, Coebergh JW, et al. Stage at diagnosis is a key explanation of differences in breast cancer survival across Europe. Int J Cancer. 2003;106:416-22.

70. de Glas NA, Bastiaannet E, de Craen AJM, van de Velde CJH, Siesling S, Liefers GJ, et al. Survival of older patients with metastasised breast cancer lags behind despite evolving treatment strategies--a population-based study. Eur J Cancer. 2015;51:310-6.

71. Dialla PO, Quipourt V, Gentil J, Marilier S, Poillot M-L, Roignot P, et al. In breast cancer, are treatments and survival the same whatever a patient's age? A population-based study over the period 1998-2009. Geriatr Gerontol Int. 2015;15(5):617-26.

72. Smith $\mathrm{IE}$, Fribbens $\mathrm{C}$. Management of breast cancer in older and frail patients. Breast. 2015;24:S159-62.

73. Instituto Nacional de Estadística. Encuesta Europea de Salud en España. 2014. https://www.msssi.gob.es/estadEstudios/estadisticas/EncuestaEuropea/ Enc_Eur_Salud_en_Esp_2014.htm. Accessed 10 Jan 2017. 
74. Instituto Nacional de Estadística. Encuesta Nacional de Salud 2011-12. 2012. https://www.msssi.gob.es/estadEstudios/estadisticas/encuestaNacional/ encuesta2011.htm Accessed 10 Jan 2017.

75. Álvaro-Meca A, Debón A, Gil Prieto R, Gil de Miguel Á. Breast cancer mortality in Spain: has it really declined for all age groups? Public Health. 2012;126:891-5.

76. Toriola AT, Colditz GA. Trends in breast cancer incidence and mortality in the United States: implications for prevention. Breast Cancer Res Treat. 2013; 138:665-73

77. Clèries R, Esteban L, Borràs J, Marcos-Gragera R, Freitas A, Carulla M, et al. Time trends of cancer incidence and mortality in Catalonia during 19932007. Clin Transl Oncol. 2014;16:18-28.

Ready to submit your research? Choose BMC and benefit from:

- fast, convenient online submission

- thorough peer review by experienced researchers in your field

- rapid publication on acceptance

- support for research data, including large and complex data types

- gold Open Access which fosters wider collaboration and increased citations

- maximum visibility for your research: over $100 \mathrm{M}$ website views per year

At BMC, research is always in progress.

Learn more biomedcentral.com/submissions 